\title{
Study of the Dynamic Mechanical Properties of Recycled Concrete Containing Ferronickel Slag Subjected to Impact
}

\author{
Caisong Luo, ${ }^{1}$ Ai Qi, ${ }^{1}$ Changlin Zhou $\mathbb{D}^{2}{ }^{2}$ Ruifeng Liu, ${ }^{3}$ Hao Qiu, ${ }^{4}$ Lin Lang, \\ and Zheming $\mathrm{Zhu}^{5}$ \\ ${ }^{1}$ School of Civil Engineering, Fuzhou University, Fuzhou 350108, China \\ ${ }^{2}$ Chengdu Surveying Geotechnical Research Institute Co., Ltd. of MCC, Chengdu 610023, China \\ ${ }^{3}$ College of Civil and Architecture Engineering, Panzhihua University, Panzhihua 617000, China \\ ${ }^{4}$ School of Transportation and Civil Engineering, Fujian Agriculture and Forestry University, Fuzhou 350002, China \\ ${ }^{5}$ Key Laboratory of Deep Underground Science and Engineering of Ministry of Education, \\ School of Architecture and Environment, Sichuan University, Chengdu 610065, China \\ Correspondence should be addressed to Changlin Zhou; jsb@mcc-yck.com
}

Received 22 February 2021; Accepted 18 June 2021; Published 1 July 2021

Academic Editor: Shuang Li

Copyright (C) 2021 Caisong Luo et al. This is an open access article distributed under the Creative Commons Attribution License, which permits unrestricted use, distribution, and reproduction in any medium, provided the original work is properly cited.

In order to study the dynamic mechanical properties of recycled concrete with ferronickel slag, dynamic experiments on cylindrical specimens $(\varphi 73 \mathrm{~mm} \times 36.5 \mathrm{~mm})$ were performed using a split Hopkinson pressure bar (SHPB) system. The effects of loading rate and recycled aggregate replacement rate on the compressive strength, toughness index, peak strain, and failure pattern of the concrete were investigated, and four different loading rates and aggregate replacement rates were selected. In addition, cohesive elements were embedded between C3D8R elements in the numerical model using Python language to simulate the failure process of the recycled concrete, and the reliability of the simulation was validated by the obtained experimental results. It was found that the peak strain of the recycled concrete was significantly higher than that of the ordinary concrete; however, its peak stress was lower than that of the ordinary concrete. In comparison to the recycled concretes containing $70 \%$ and $100 \%$ recycled coarse aggregates (RCAs), the toughness index amplification of the recycled concrete containing $30 \%$ RCAs was the most obvious. The failure pattern and mechanical properties of the numerical model were consistent with those of the test specimens, thus validating the reliability of the numerical simulation.

\section{Introduction}

Ferronickel slag (FNS) is an industrial metallurgy slag produced in ferronickel manufacturing processes. It is estimated that about 14 tons of slag are generally produced per ton of nickel [1]. China produces about 4 million tons of slag every year [2]; however, less than $10 \%$ of slag is actually utilized. FNS accumulates in the open air, and its harmful substances cause soil quality to decline. Additionally, the dust dispersion of waste during transportation reduces air quality. Therefore, it is pointed out that the recovery and utilization of FNS have good economic and social benefits [3-5]. Moreover, recycled concretes with ferronickel slag (RCFNS) have good strength [6].
The chemical composition of FNS mainly includes $\mathrm{SiO}_{2}$, $\mathrm{MgO}, \mathrm{CaO}, \mathrm{Al}_{2} \mathrm{O}_{3}$, and $\mathrm{Fe}_{2} \mathrm{O}_{3}$ [7], and crystalline minerals in nickel-iron slag consist of enstatite, forsterite, and diopside [8]. The content of amorphous minerals in FNS is generally higher than 50\% [9]. FNS powder has a pozzolanic activity and is a potential mineral admixture for concrete. Dourdounis et al. [10] studied the utilization of ferronickel electroreduction furnace (FeNi-ERF) slag for the production of high-alumina cement and found that the reduction smelting process of ERF slag with limestone and low-grade diasporic bauxite had considerable potential for optimization. Katsiotis et al. [11] studied the performance and hydration of a mixed cement containing FNS powder and noticed that the addition of FNS reduced the water requirement of the mixed cement 
and prolonged the setting time. Ding et al. [12] found that the FNS powder-containing concrete exhibited good performance at a suitable replacement rate.

Although the application of recycled aggregate concretes (RAC) can reduce construction waste and save natural resources, their strength is lower than that of natural aggregate concretes [13]. Etxeberria et al. [14] studied the production of RAC with four different recycled aggregate replacement rates and found that the RAC with $25 \%$ of recycled coarse aggregates (RCA) achieved the same mechanical properties as those of conventional concretes. Limbachiya et al. [15] studied the effects of RCA content on the ceiling strength, bulk engineering, and durability of RAC and reported that $30 \%$ coarse RCA had no effect on the concrete strength; however, the concrete strength decreased with the increase of RCA content.

Nowadays, due to the increase of extreme incidents, such as chemical explosions, terrorist attacks, high-speed car crashes, and explosions, widespread concern about the security of building structures is raised. In an explosion, tremendous energy is released in a very short period and causes great damage. Therefore, in order to apply RAC members in structural engineering, it is necessary to study their dynamic behavior under impact loading. Rao et al. [16] investigated the behavior of RAC beams with varied RAC ratios subjected to low-velocity impacts and found that 25\% RCA did not influence the concrete strength. Li et al. [17] investigated the effects of nanoparticles on the dynamics behavior of RAC members under impact loading by a split Hopkinson pressure bar (SHPB) system and found that nano- $\mathrm{SiO}_{2}$ particles were more effective to improve the dynamic compressive strength of RAC. Mastali et al. [18] studied the impact resistance and mechanical properties of self-compacting concrete reinforced with recycled glass fiber-reinforced polymers (GFRP) and noticed that the impact resistance and mechanical properties of the concrete were linearly correlated. Li et al. [19] investigated the behavior of a recycled aggregate concrete-filled steel tube (RACFST) at elevated temperatures by experimental and numerical studies and reported that the impact behavior of the tube was improved with the increasing steel ratio.

In view of the above analysis, the strength of recycled concrete is generally lower than that of natural aggregate concrete, and the ferronickel slag is helpful to improve the strength of concrete. Therefore, in order to promote the application of recycled concrete in impact engineering, ferronickel slag was used to make up for the lack of bearing capacity of recycled concrete, and the impact tests of recycled concrete containing ferronickel slag (RCFS) were carried out to determine its dynamic mechanical properties. In the present work, dynamic experiments of RCFS specimens were performed using a SHPB system at different replacement rates of RCA and loading rates. The compressive strength, toughness index, peak strain, and failure pattern of the concrete specimens were analyzed. In addition, the failure process of recycled concrete with ferronickel slag was simulated in ABAQUS software. The failure mechanism of the numerical model was analyzed, and the reliability of the numerical simulation was validated by experimental results.

\section{Experiment}

2.1. Materials. Both the ordinary concrete and the recycled concrete were composed of P.O 42.5 cement, and their strengths were $60 \mathrm{MPa}$. Blast furnace FNS prepared by water quenching was used in this research. The density, specific surface area, average particle diameter, and particle size distribution of FNS were $2.86 \mathrm{~g} / \mathrm{cm}^{3}, 425.6 \mathrm{~m}^{2} / \mathrm{kg}$, $13.953 \mu \mathrm{m}$, and $1-100 \mu \mathrm{m}$, respectively. The primary components of FNS and cement are presented in Table 1. The $\mathrm{X}$-ray diffraction (XRD) curve of FNS is displayed in Figure 1 . The main components of FNS were $\mathrm{CaCO}_{3}, \mathrm{MgAlO}_{4}$, and $(\mathrm{Mg}, \mathrm{Fe})_{2} \mathrm{SiO}_{4}$. The main physical properties of cement are presented in Table 2 .

The water-cement ratio of the ordinary concrete specimen (N0-60) was 0.32, and no RCA was used in this concrete. In order to ensure the fluidity and compactness of the concrete mixing process, a water reducing agent and silica fume are added into the ordinary concrete and the recycled concrete. Moreover, fine aggregates of natural river sand with a fineness modulus of 2.7 were added to both types of concretes. RCAs of the recycled concrete were crushed particles $($ size $=16 \mathrm{~mm})$ of C60 ordinary concrete. The mixing proportions of these two types of concretes are depicted in Table 3.

2.2. Specimens. Impact tests of the two types of concrete were carried out by a SHPB system with a diameter of $80 \mathrm{~mm}$. The main parameters of the tests were the loading rate and the replacement rate of RCA. The diameter and height of the test specimens were $73 \mathrm{~mm}$ and $36.5 \mathrm{~mm}$, respectively (Figure 2). The propagation of one-dimensional stress waves in the specimens was assumed, and the inertial and dispersion effects under an impact were eliminated [20]. After pouring the specimens, the standard curing was carried out for 28 days, and then the cross sections of the specimens were polished to ensure the flatness requirements of the International Society for Rock Mechanics (ISRM).

In order to facilitate the analysis of test data, the specimens were numbered. For example, in the R30-60-1400 specimen, $\mathrm{R}$ represents recycled concrete, 30 represents $30 \%$ RCAs, 60 represents the concrete strength of $60 \mathrm{MPa}$, and 1400 represents the loading rate of $1400 \mathrm{GPa} / \mathrm{s}$.

2.3. Experimental Equipment. SHPB systems have a history of more than 100 years and are widely used to determine the dynamic mechanical properties of materials [21-25].

The pressure bar of the SHPB system used in this experiment was made of high-strength alloy steel (elastic modulus $=210 \mathrm{GPa}$ and Poisson's ratio $=0.25$ ). The diameter of the bar was $80 \mathrm{~mm}$, and the length of the incident and transmitted bars was $3000 \mathrm{~mm}$ and $2040 \mathrm{~mm}$, respectively. A damper was installed behind the transmission bar. The air pressure of the launching device of the SHPB system was electronically controlled to ensure a stable launching speed of the impact bar. In addition, an infrared velocimeter was used to capture the speed of the impact bar. The test device is displayed in Figure 3. 
TABle 1: Primary components of FNS and cement (\%).

\begin{tabular}{lcccccrr}
\hline & $\mathrm{SiO}_{2}$ & $\mathrm{CaO}$ & $\mathrm{Al}_{2} \mathrm{O}_{3}$ & $\mathrm{MgO}$ & $\mathrm{Fe}_{2} \mathrm{O}_{3}$ & $\mathrm{SO}_{3}$ & $\mathrm{LOI}^{*}$ \\
\hline FNS & 37.47 & 24.82 & 21.37 & 10.53 & 1.72 & 0.32 & 0.68 \\
Cement & 21.69 & 62.55 & 4.38 & 2.05 & 3.34 & 2.89 & 1.59 \\
\hline
\end{tabular}

${ }^{*}$ Loss on ignition.

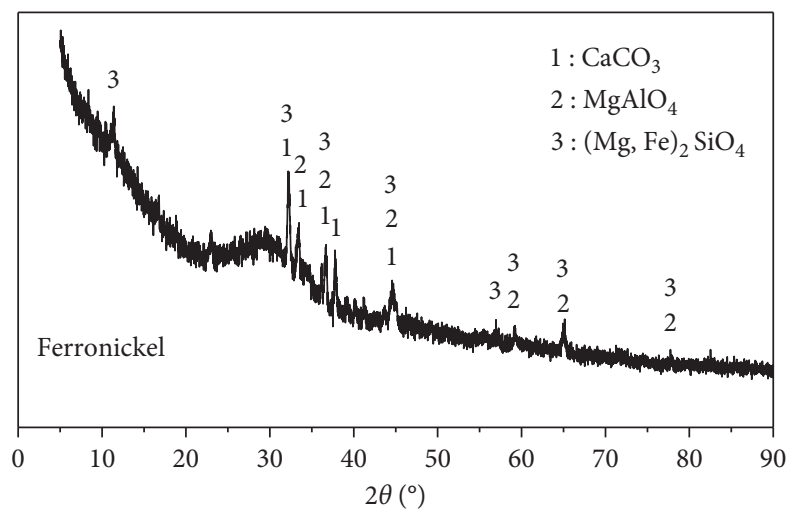

FIGURE 1: XRD curve of FNS.

TABle 2: Physical properties of cement.

\begin{tabular}{|c|c|c|c|c|c|c|c|c|c|c|}
\hline \multirow{2}{*}{$\begin{array}{l}\text { Specific surface area } \\
\left(\mathrm{m}^{2} / \mathrm{kg}\right)\end{array}$} & \multirow{2}{*}{$\begin{array}{c}\text { Water requirement of standard } \\
\text { consistency }(\%)\end{array}$} & \multicolumn{2}{|c|}{ Setting time $(\mathrm{min})$} & \multirow{2}{*}{ Stability } & \multicolumn{3}{|c|}{$\begin{array}{c}\text { Flexural } \\
\text { strength }(\mathrm{MPa})\end{array}$} & \multicolumn{3}{|c|}{$\begin{array}{c}\text { Compressive } \\
\text { strength }(\mathrm{MPa})\end{array}$} \\
\hline & & $\begin{array}{l}\text { Initial setting } \\
\text { time }\end{array}$ & $\begin{array}{l}\text { Final setting } \\
\text { time }\end{array}$ & & $3 \mathrm{~d}$ & $7 d$ & $28 \mathrm{~d}$ & $3 \mathrm{~d}$ & $7 \mathrm{~d}$ & $28 \mathrm{~d}$ \\
\hline 345 & 28.1 & 193 & 253 & Qualified & 4.98 & 6.97 & 9.35 & 24.02 & 40.27 & 51.03 \\
\hline
\end{tabular}

TABLE 3: Mixing proportions of ordinary and recycled concrete.

\begin{tabular}{lccccccccc}
\hline \multirow{2}{*}{ Specimen } & \multirow{2}{*}{ RR (\%) } & \multicolumn{7}{c}{ Mixing ratio $\left(\mathrm{kg} / \mathrm{m}^{3}\right)$} \\
& & Water & Cement & Sand & Natural coarse aggregate & RCA & Ferronickel slag & Silica fume & Superplasticizer \\
\hline N0-60 & 0 & 175 & 382 & 604 & 1074 & 0 & 109 & 55 & 6.55 \\
R30-60 & 30 & 181 & 382 & 604 & 752 & 322 & 109 & 55 & 6.55 \\
R70-60 & 70 & 189 & 382 & 604 & 322 & 752 & 109 & 55 & 6.55 \\
R100-60 & 100 & 195 & 382 & 604 & 0 & 1075 & 109 & 55 & 6.55 \\
\hline
\end{tabular}

$\mathrm{N}$ and R represent the ordinary concrete and the recycled concrete, respectively; RR is the replacement rate of RCA; 60 represents the concrete strength of $60 \mathrm{MPa}$.

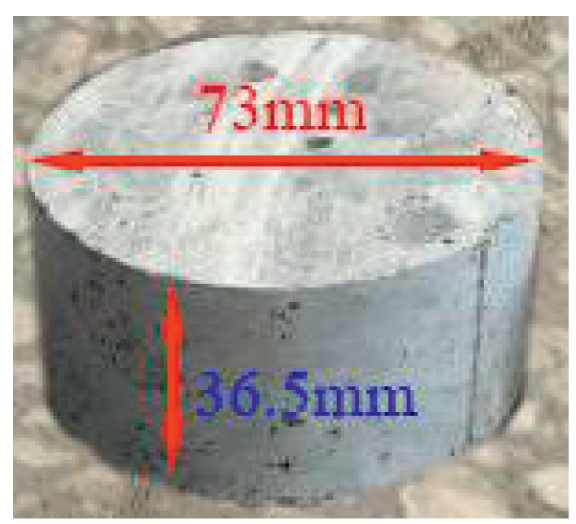

Figure 2: Test specimen. 
In order to investigate the influence of loading rate on the mechanical properties of the specimens, four different loading rates of $1400 \mathrm{GPa} / \mathrm{s}, 1500 \mathrm{GPa} / \mathrm{s}, 1600 \mathrm{GPa} / \mathrm{s}$, and $1700 \mathrm{GPa} / \mathrm{s}$ were selected.

A DH3840 ultradynamic strain indicator was used to capture voltage signals of the pressure bar based on the halfbridge method. Strain gauges on the incident and transmission bars were connected to the superdynamic strain indicator. Voltage fluctuations of the strain gauges were caused by stress waves, and the detected voltage signals were transformed into force versus time by equations (1) and (2) (Figure 4):

$$
\begin{aligned}
\varepsilon & =\frac{4 U_{0}}{n E_{0} K}, \\
F_{L}(t) & =E A\left[\varepsilon_{i}(t)+\varepsilon_{r}(t)\right], \\
F_{R} & =E A \varepsilon_{t}(t),
\end{aligned}
$$

where $K$ denotes the sensitivity coefficient of the strain gauges, $U_{0}$ denotes the output voltage signal, $E_{0}$ denotes the bridge voltage, $n$ denotes the gain coefficient $(n=300), E$ is Young's modulus of the incident and transmission bars, $A$ is the cross-sectional area of the bars, and $\varepsilon_{i}, \varepsilon_{r}$, and $\varepsilon_{t}$ are the recorded strains.

It is noticeable from Figure 4 that superposition waves were formed by incident waves, and reflected waves were in good agreement with transmitted waves. Therefore, the dynamic force balance of the specimens could be realized when stress waves propagated across the specimens several times, and the quasistatic theory was used to analyze the specimens.

\section{Test Results and Analysis}

In this research, four types of concrete specimen (N0-60, R30-60, R70-60, and R100-60) were investigated. For each type, four loading rates were selected, and three specimens were tested under each loading rate. A total of 48 specimens were prepared in this test. Due to a large number of test specimens, some typical test results were selected for the analysis.

3.1. Failure Phenomenon and SEM Micrograph. Taking the R30-60 specimen as an example, the detected failure patterns were divided into four grades over a wide range of loading rates (Figure 5). Grade 1 indicates that the specimen was split into two parts under the loading rate of $1400 \mathrm{GPa} / \mathrm{s}$; however, these two parts experienced little damage and no spalling. Grade 2 indicates that the specimen was split into numerous fragments under the loading rate of $1500 \mathrm{GPa} / \mathrm{s}$. Grade 3 indicates that the specimen still had numerous fragments under the loading rate of $1600 \mathrm{GPa} / \mathrm{s}$; however, their volume was smaller than that of Grade 2. Grade 4 indicates that the specimen was completely crushed under the loading rate of $1700 \mathrm{GPa} / \mathrm{s}$.

Figure 6 displays the SEM micrographs of four types of specimens (N0-60-1400, R30-60-1400, and R70-60-1400) under a local magnification of 6000 times. The N0-60-1400 specimen contained a large amount of hydration products (Figure 6(a)). A large amount of $\mathrm{Al}_{2} \mathrm{O}_{3}$ and $\mathrm{SO}_{2}$ was present in FNS, and these substances reacted with $\mathrm{Ca}(\mathrm{OH})_{2}$ produced by cement. The C-S-H gel could fill porosity in the specimen and combine aggregates and cementitious materials more closely. In the R30-60-1400 specimen, hydration products generated on the surface contained a large amount of acicular ettringite (Figure 6(b)). The formation of ettringite led to an expansion of this concrete and affected the interface strength between aggregates and the mortar. In the R70-60-1400 specimen, numerous granular substances and holes were present on the surface, the boundary between the mortar and aggregates was prominent, and the adhesion between particles was weak (Figure 6(c)).

3.2. Relationship between Loading Rate and Stress-Strain. Figure 7 displays the mechanical properties of the concrete specimens (N0-60, R30-60, R70-60, and R100-60) under the loading rates of $1400 \mathrm{GPa} / \mathrm{s}$ and $1700 \mathrm{GPa} / \mathrm{s}$. The stressstrain curves were linear in the early stage and nonlinear in the later stage [26].

It is clear from Figure 7 (a) that when the loading rate was $1400 \mathrm{GPa} / \mathrm{s}$, the peak stress of the R30-60-1400 specimen was $0.1 \%$ lower than that of N0-60-1400. When the loading rate reached $1700 \mathrm{GPa} / \mathrm{s}$, the peak stress of the N0-60-1700 specimen was $9 \%$ higher than that of R30-60-1700. In comparison to the N0-60 specimen, the peak stress of the R30-60 concrete increased more slowly with increasing loading rate.

It is noticeable from Figure 7 (b) that when the loading rate was $1400 \mathrm{GPa} / \mathrm{s}$, the peak stress of the $\mathrm{R} 70-60-1400$ specimen was higher than that of N0-60-1400. When the loading rate reached $1700 \mathrm{GPa} / \mathrm{s}$, the peak strain of the R7060-1700 specimen was higher than that of N0-60-1700; however, its peak stress was lower than that of N0-60-1700. In comparison to the N0-60 specimen, the peak stress of the R70-60 concrete increased more slowly with the increasing loading rate.

When the RCA content in the recycled concretes varied from $30 \%$ to $100 \%$, the peak strain of the recycled concretes was significantly higher than that of the N0-60 specimen; however, their peak stress was lower than that of N0-60. When the replacement rate of RCA reached $100 \%$, the peak stress decreases by $21 \%$ under the loading rate of $1700 \mathrm{GPa} / \mathrm{s}$.

3.3. Toughness Index. When a specimen is destroyed under impact, the ability of the specimen to absorb the impact energy is called toughness, which is used to evaluate the strength and ductility of materials. The area enclosed by a stress-strain curve and coordinate axes is defined as toughness [27-30]. The toughness values of four types of concretes are presented in Figure 8, and the toughness index was expressed by $T$.

The toughness index of the N0-60 specimen increased from $85.76 \mathrm{~J} / \mathrm{cm}^{3}$ to $138.24 \mathrm{~J} / \mathrm{cm}^{3}$ (increment of $52.48 \mathrm{~J} / \mathrm{cm}^{3}$ ) with the increasing loading rate from $1400 \mathrm{GPa} / \mathrm{s}$ to $1700 \mathrm{GPa} / \mathrm{s}$. The toughness index of the R30-60 specimen increased from $71.37 \mathrm{~J} / \mathrm{cm}^{3}$ to $161.32 \mathrm{~J} / \mathrm{cm}^{3}$ (increment of 


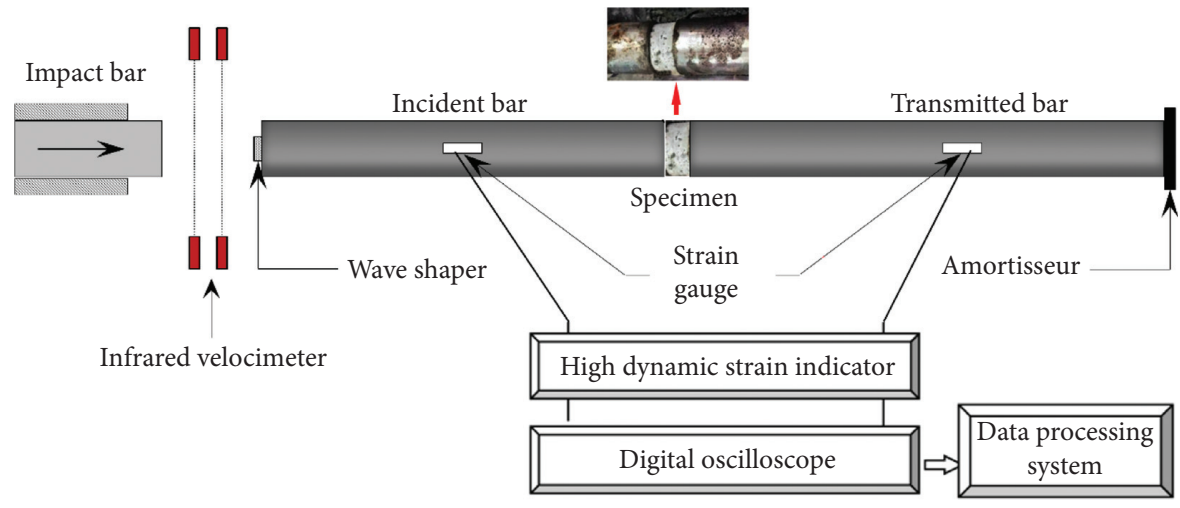

FIgURE 3: SHPB system and the test specimen.

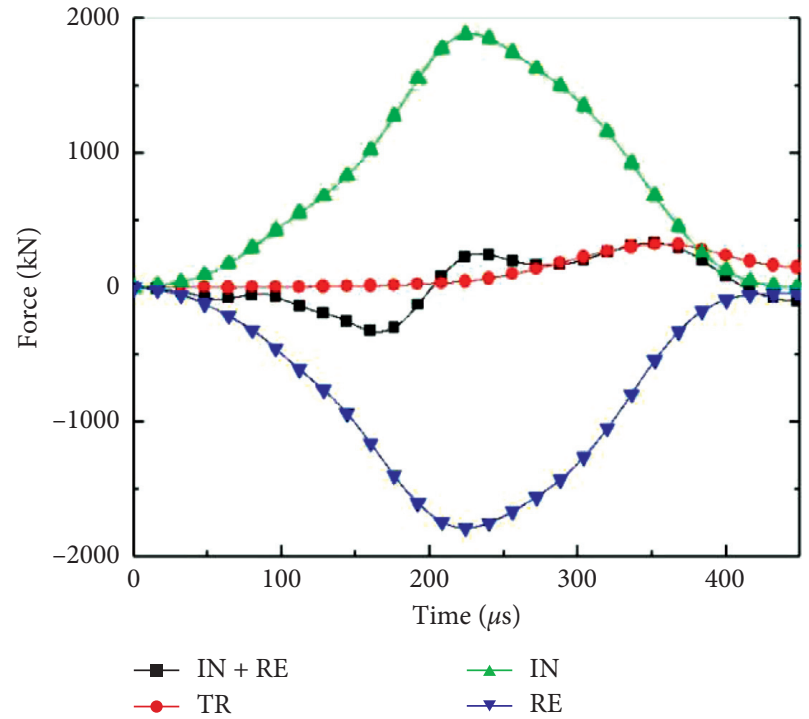

(a)

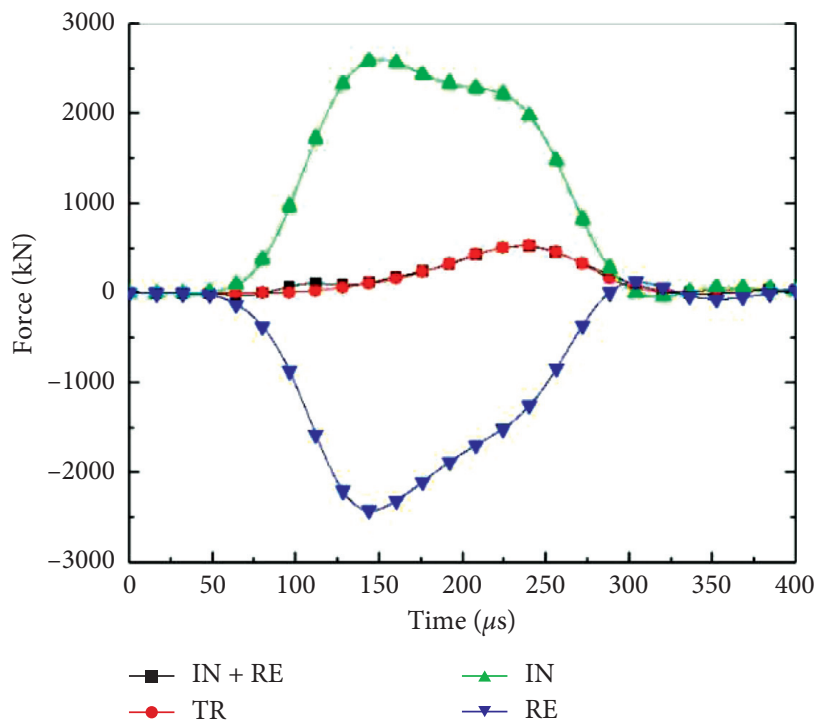

(c)

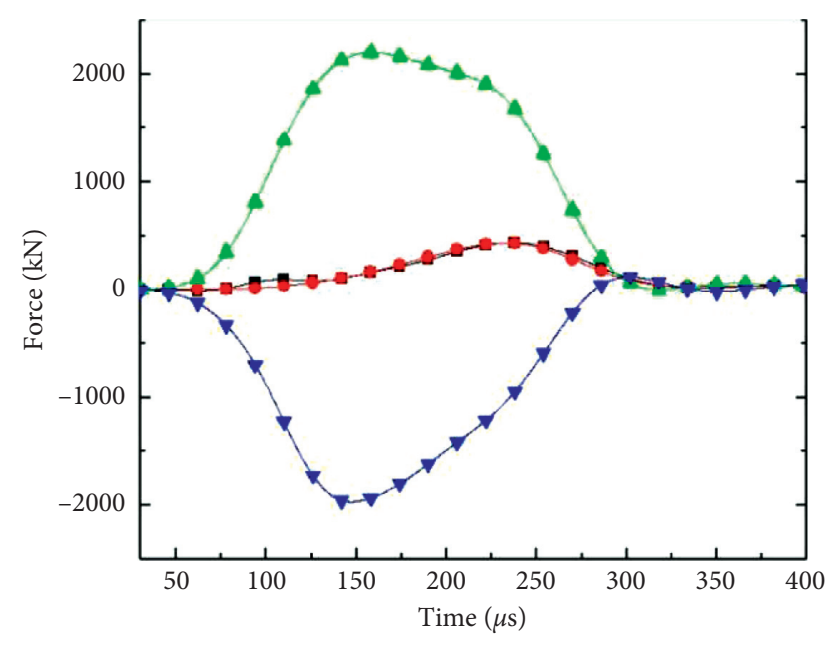

$\begin{array}{ll}\rightarrow \mathrm{IN}+\mathrm{RE} & \rightarrow \mathrm{IN} \\ \rightarrow \mathrm{TR} & \rightarrow \mathrm{RE}\end{array}$

(b)

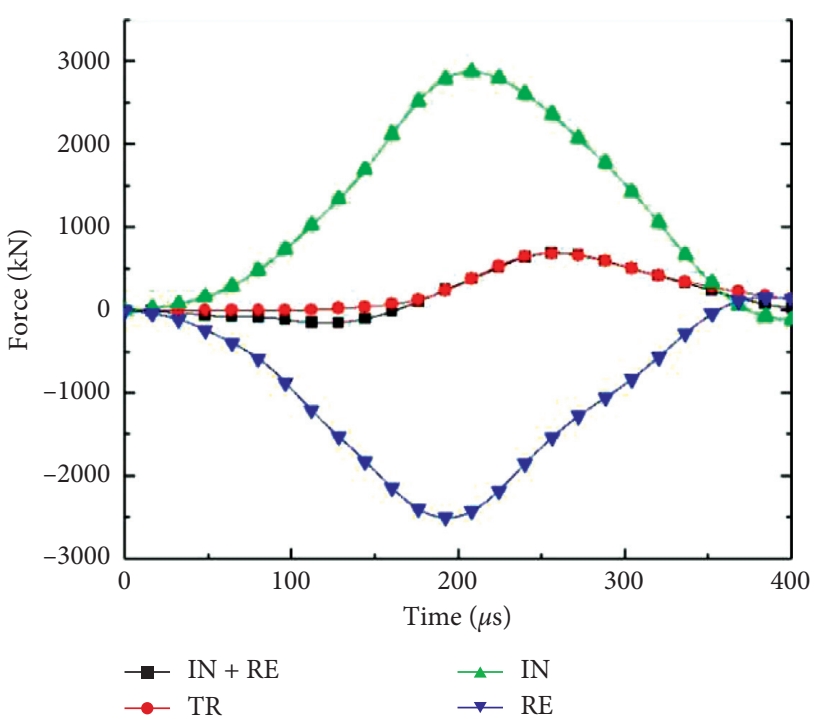

(d)

FiguRE 4: Curves of force versus time for R100-60 specimens: (a) R100-60-1400 specimen, (b) R100-60-1500 specimen, (c) R100-60-1600 specimen, and (d) R100-60-1700 specimen. 


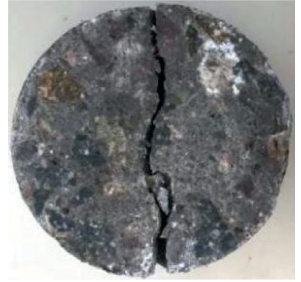

(a)

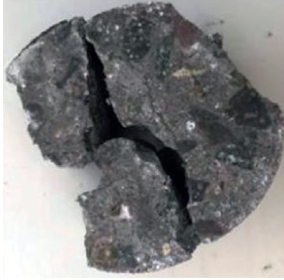

(b)

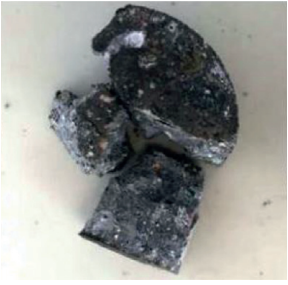

(c)

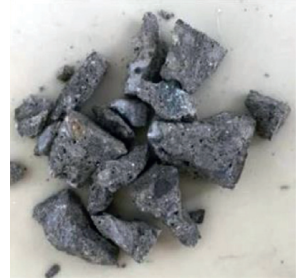

(d)

Figure 5: Failure patterns of the R30-60 specimen: (a) grade 1, (b) grade 2, (c) grade 3, and (d) grade 4.
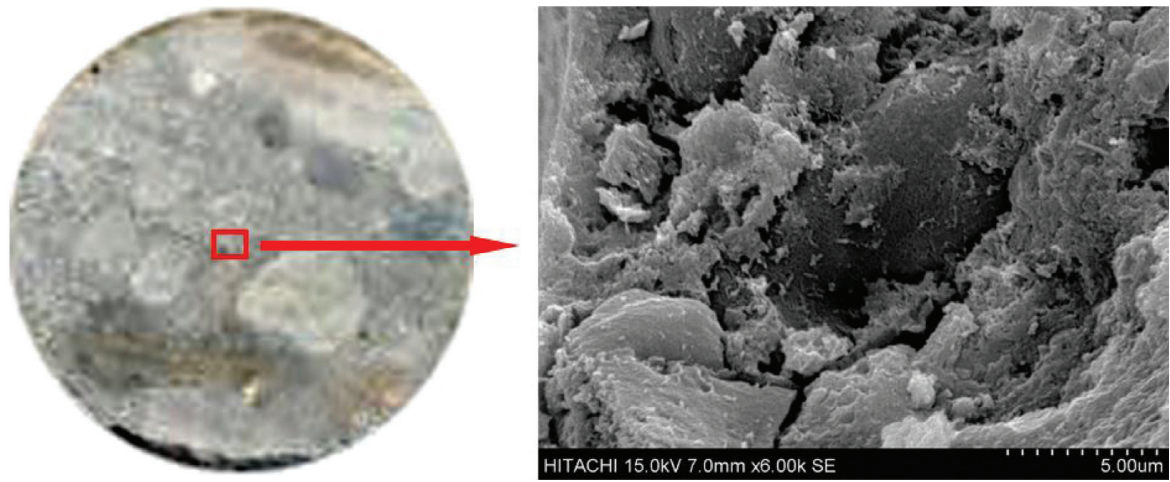

(a)
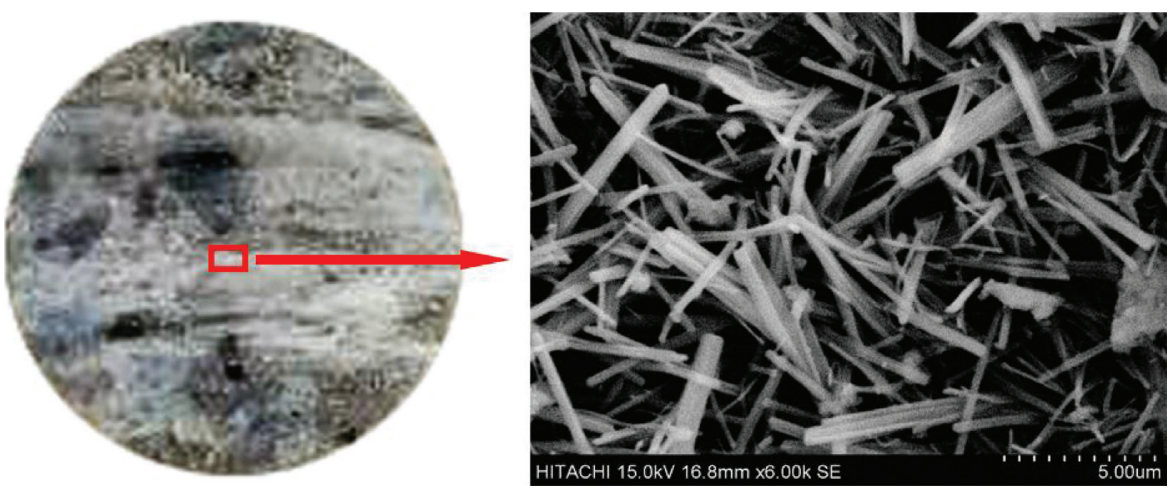

(b)
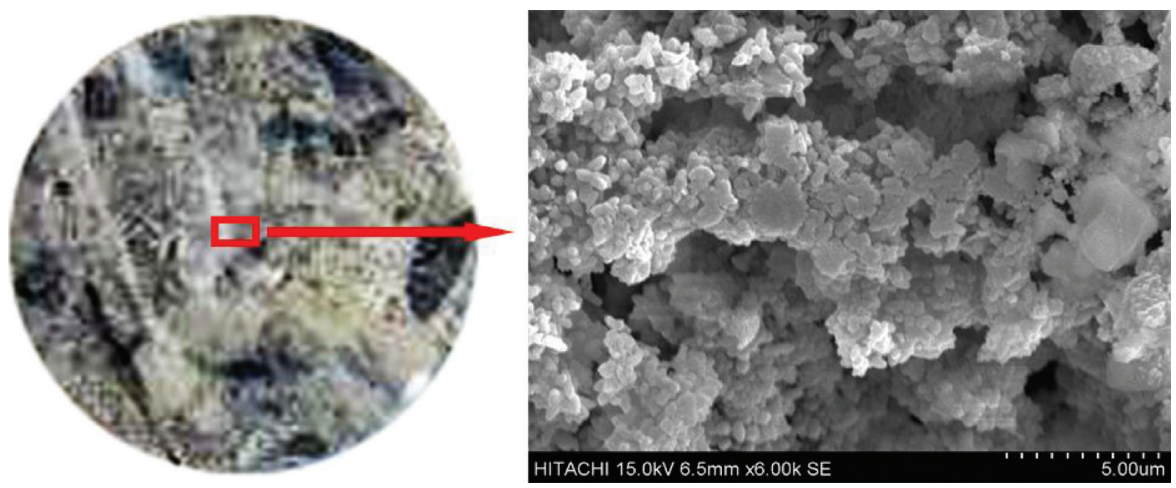

(c)

FiguRE 6: SEM microstructures of four types of specimens: (a) N0-60-1400 specimen, (b) R30-60-1400 specimen, and (c) R70-60-1400 specimen.

$89.95 \mathrm{~J} / \mathrm{cm}^{3}$ ) as the loading rate increased from $1400 \mathrm{GPa} / \mathrm{s}$ to $1700 \mathrm{GPa} / \mathrm{s}$. The toughness index of the R70-60 specimen increased from $55.21 \mathrm{~J} / \mathrm{cm}^{3}$ to $126.25 \mathrm{~J} / \mathrm{cm}^{3}$ (increment of
$71.04 \mathrm{~J} / \mathrm{cm}^{3}$ ) when the loading rate increased from $1400 \mathrm{GPa} /$ $s$ to $1700 \mathrm{GPa} / \mathrm{s}$. The toughness index of the R100-60 specimen increased by only $55.32 \mathrm{~J} / \mathrm{cm}^{3}$. Therefore, the 


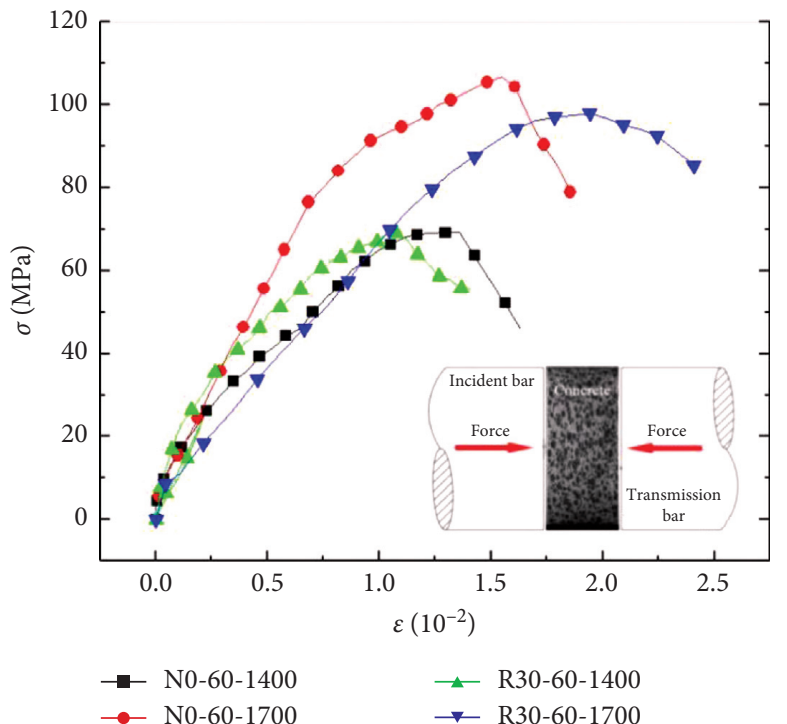

(a)

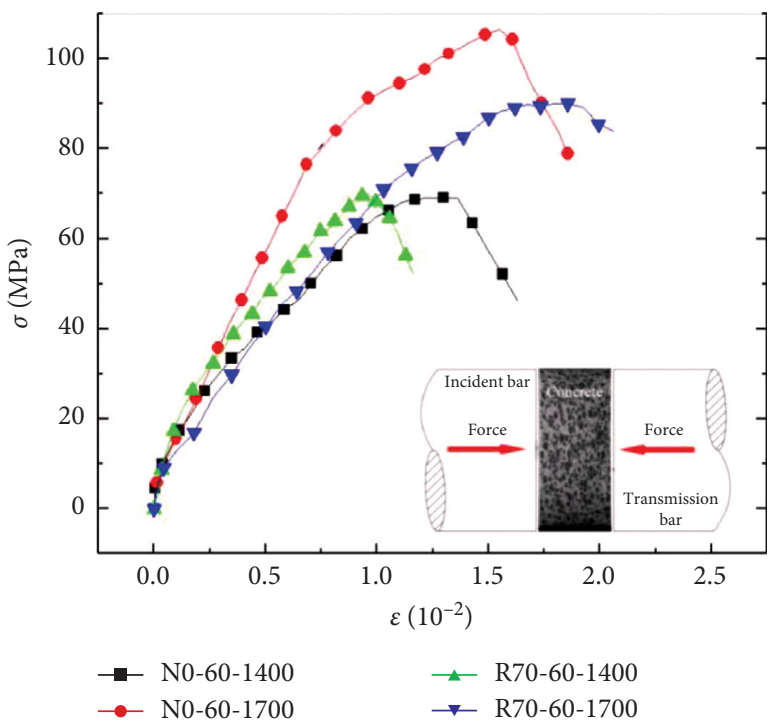

(b)

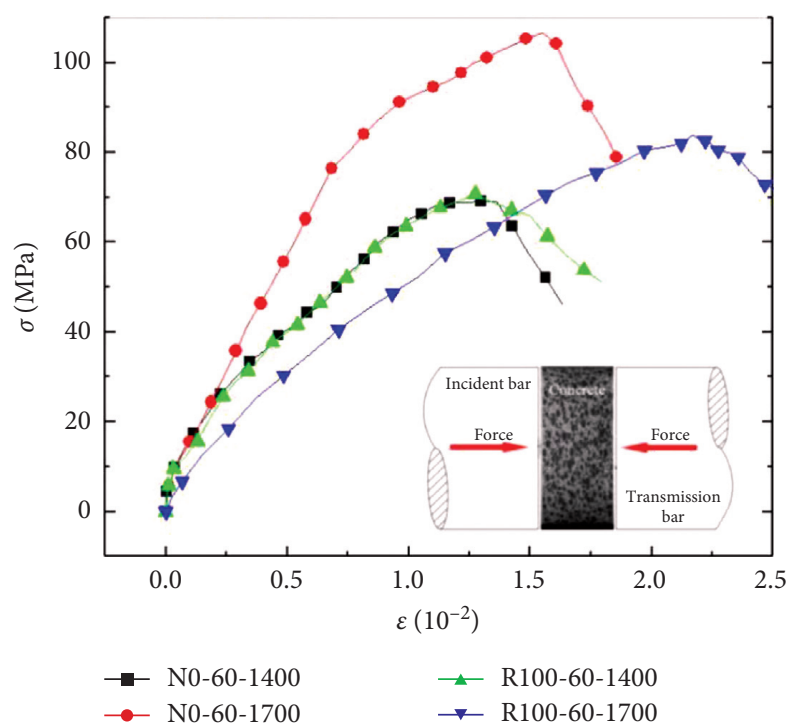

(c)

FiguRE 7: Stress-strain curves of four types of concrete specimens: (a) stress-strain curves of N0-60 and R30-60 specimens, (b) stress-strain curves of N0-60 and R70-60 specimens, and (c) stress-strain curves of N0-60 and R100-60 specimens.

difference of the toughness index of the recycled concrete with the increasing loading rate from $1400 \mathrm{GPa} / \mathrm{s}$ and $1700 \mathrm{GPa} / \mathrm{s}$ decreased with the increase of RCA content.

Under the same replacement rate of RCA, the toughness index of the recycled concrete increased with the increase of the loading rate. In comparison to the recycled concretes containing $70 \%$ and $100 \%$ RCAs (R70-60 and R100-60 specimens, respectively), the toughness index increase of the R30-60 specimen was the most obvious.

3.4. Effect of the Replacement Rate of RCA on Peak Strain. Peak strain is an important index to indicate the deformation and instability of a specimen after an impact. Figure 9 displays the relationship between the peak strain of each specimen and the loading rate.
It is clear that the peak strain of each concrete increased with the increase of the loading rate. When the loading rate increased from $1400 \mathrm{GPa} / \mathrm{s}$ to $1700 \mathrm{GPa} / \mathrm{s}$, the peak strains of N0-60, R30-60, and R100-60 increased by $1.9 \times 10^{-3}$, $8.67 \times 10^{-3}$, and $2.166 \times 10^{-2}$, respectively.

Table 4 presents a summary of the obtained test results. The average peak strain, average toughness index, and average peak stress of the specimens had an increasing trend with the increase of the loading rate. When the loading rate was $1700 \mathrm{GPa} / \mathrm{s}$, the N0-60 specimen had the largest average peak stress, whereas the average peak strain of R100-60 was found to be the largest. When the loading rate was $1400 \mathrm{GPa} /$ $\mathrm{s}$, all four types of specimens experienced only cracking phenomenon. When the loading rate varied between $1500 \mathrm{GPa} / \mathrm{s}$ and $1600 \mathrm{GPa} / \mathrm{s}$, large particle fragments were 


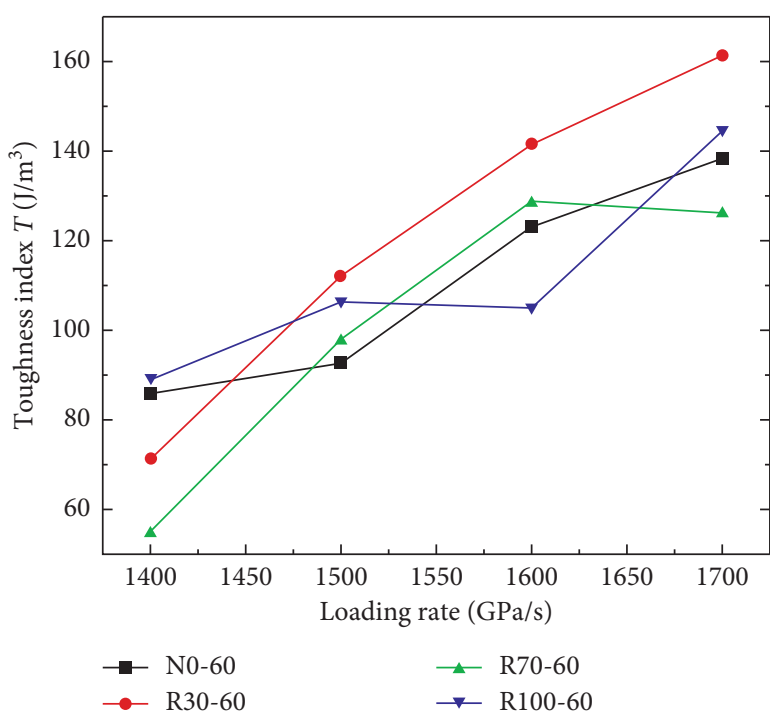

FIGURE 8: Effect of loading rates on the toughness index.

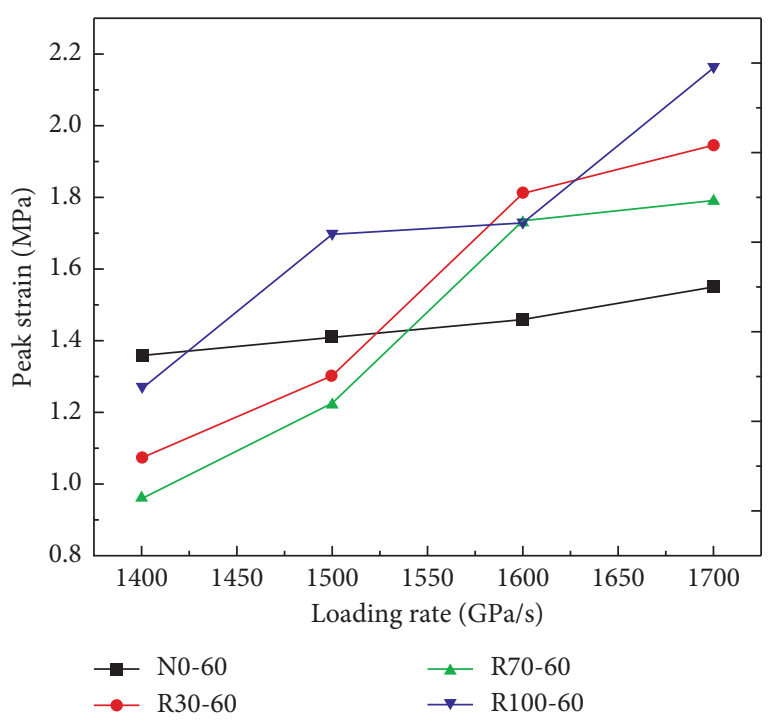

FIGURE 9: Effect of loading rates on peak strain.

generated in all four types of specimens. When the loading rate was $1700 \mathrm{GPa} / \mathrm{s}$, all four types of specimens were crushed.

\section{Numerical Simulation}

Taking the R100-60-1700 specimen as an example, the secondary development of ABAQUS was carried out by Python language to realize the batch embedding of cohesive elements and the random generation of coarse aggregates in the numerical model, and by this method, the random crack propagation and random element shedding of the model were realized. Moreover, the reliability of the numerical simulation was validated by the obtained experimental results.

4.1. Cohesive Model. The cohesive model is first introduced by Barenblatt [31] to simulate the decohesion of atomic lattices by the traction-separation law. The cohesive model of
ABAQUS also adopts this damage mechanics model. The linear triangular cohesive model shown in Figure 10 is generally used to simulate the fracture of brittle materials. $\delta_{m}^{0}, \delta_{m}^{f}$, and $G^{\mathrm{C}}$ in Figure 10 represent the initial damage displacement, the effective displacement of traction force, and the energy release rate, respectively.

4.2. Damage Initiation Criteria. When the contact traction or separation reaches the peak point $A$ in Figure 10, the damage of the cohesive element initiates. In the present research, the damage initiation criteria of ABAQUS cohesive elements adopted the maximum nominal stress criterion.

$$
f=\max \left\{\frac{\sigma_{n}}{\sigma_{n}^{o}}, \frac{\tau_{s}}{\tau_{s}^{o}}, \frac{\tau_{t}}{\tau_{t}^{o}}\right\},
$$

where $\sigma_{n}$ is normal traction force on the fracture surface, $\tau_{s}$ and $\tau_{t}$ are two tangential traction forces on the fracture surface, and $\sigma_{n}^{0}, \tau_{s}^{0}$, and $\tau_{t}^{0}$ are the peak values of anisotropic nominal stress. When $f=1.0$, the damage starts.

4.3. Damage Evolution. The damage evolution law describes that the cohesive model reaches the corresponding initiation criterion during the impact, and the cohesive stiffness begins to degenerate. The degradation process is indicated by the straight line $A B$ in Figure 9. The damage process of cohesive elements can be expressed as

$$
\begin{aligned}
\sigma_{n} & = \begin{cases}(1-D) \bar{\sigma}_{n}, & \bar{\sigma}_{n} \geq 0, \\
\bar{\sigma}_{n}, & \text { otherwise, }\end{cases} \\
\tau_{s} & =(1-D) \bar{\sigma}_{s}, \\
\tau_{t} & =(1-D) \bar{\sigma}_{t},
\end{aligned}
$$

where $\sigma_{n}, \tau_{s}$, and $\tau_{t}$ are the contact stress components predicted by the elastic traction-separation behavior for the current separation without damage $D$ (damage factor). If damage evolution is modeled, $D$ monotonically evolves from 0 to 1 upon further loading after the initiation of damage.

4.4. Numerical Model. ABAQUS, a commercial finite element software, provides $\mathrm{COH} 3 \mathrm{D} 8$ elements to simulate crack propagation. Crack propagation along any path can be realized by the batch embedding of $\mathrm{COH} 3 \mathrm{D} 8$ elements and is affected by the cohesive strength. The functions of ABAQUS software cannot implement the batch embedding of COH3D8 elements into a model. However, the batch embedding of COH3D8 elements can be realized by processing the INP file in ABAQUS using Python language. Therefore, the node number of C3D8R elements in a model can be obtained, and COH3D8 elements with an extremely thin thickness are formed by the node number of C3D8R elements (shown in region $A$ of Figure 11). By this method, cracks can propagate randomly between C3D8R elements during an impact, and C3D8R elements in the model can be separated. 
TABle 4: Dynamic impact test results.

\begin{tabular}{|c|c|c|c|c|c|}
\hline Specimen & $\begin{array}{l}\text { Loading rate } \\
(\mathrm{GPa} / \mathrm{s})\end{array}$ & Average toughness index $\left(\mathrm{J} / \mathrm{cm}^{3}\right)$ & Average peak strain $\left(10^{-2}\right)$ & Average peak stress $(\mathrm{MPa})$ & Failure pattern \\
\hline N0-60-1400 & 1400 & 85.76 & 1.361 & 69.11 & Crack \\
\hline N0-60-1500 & 1500 & 92.70 & 1.411 & 81.01 & Fragmentation \\
\hline N0-60-1600 & 1600 & 122.90 & 1.461 & 90.81 & Fragmentation \\
\hline N0-60-1700 & 1700 & 138.24 & 1.551 & 106.65 & Comminution \\
\hline R30-60-1400 & 1400 & 71.37 & 1.076 & 69.03 & Crack \\
\hline R30-60-1500 & 1500 & 111.96 & 1.301 & 79.28 & Fragmentation \\
\hline R30-60-1600 & 1600 & 141.69 & 1.814 & 87.89 & Fragmentation \\
\hline R30-60-1700 & 1700 & 161.32 & 1.943 & 97.89 & Comminution \\
\hline R70-60-1400 & 1400 & 55.21 & 0.963 & 69.81 & Crack \\
\hline R70-60-1500 & 1500 & 98.20 & 1.226 & 80.22 & Fragmentation \\
\hline R70-60-1600 & 1600 & 129.04 & 1.732 & 87.42 & Fragmentation \\
\hline R70-60-1700 & 1700 & 126.25 & 1.793 & 90.14 & Comminution \\
\hline $\begin{array}{l}\text { R100-60- } \\
1400\end{array}$ & 1400 & 89.35 & 1.274 & 70.68 & Crack \\
\hline $\begin{array}{l}\text { R100-60- } \\
1500\end{array}$ & 1500 & 106.58 & 1.700 & 75.98 & Crack \\
\hline $\begin{array}{l}\text { R100-60- } \\
1600\end{array}$ & 1600 & 105.11 & 1.733 & 79.93 & Fragmentation \\
\hline $\begin{array}{l}\text { R100-60- } \\
1700\end{array}$ & 1700 & 144.58 & 2.166 & 83.8 & Comminution \\
\hline
\end{tabular}

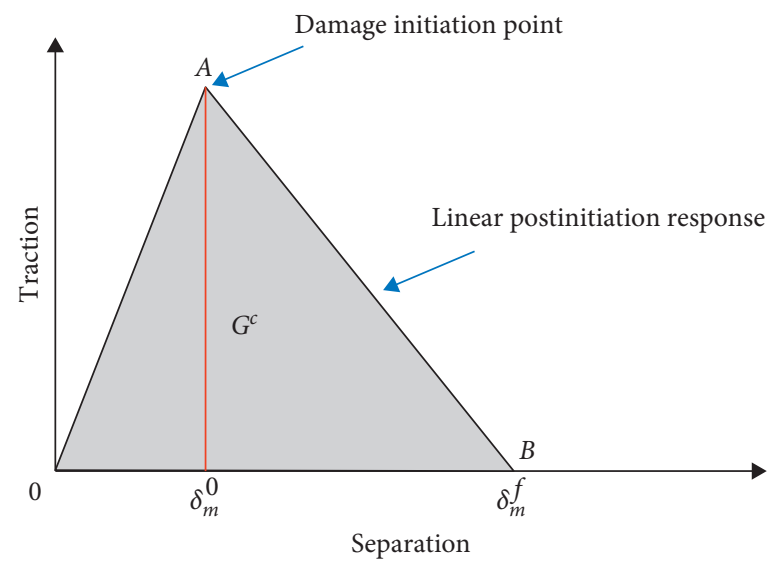

FIgURE 10: Cohesive model.

Figure 11 shows the 8-node hexahedral linear reduced integral element (C3D8R). Compared with the complete integration element, the linear reduced integration element only contains one integration point in the center of the element, while the number of integration points of the quadratic reduced integration element is the same as that of the linear complete integration element. The linear reduced integral element has the following advantages: (1) it is not easy to shear self-locking under bending load; (2) the result of displacement is more accurate; and (3) when the mesh is distorted, the accuracy of the analysis will not be greatly affected.

Therefore, C3D8R elements are widely used to establish the numerical model of concrete. When the cohesive elements are embedded, the C3D8R elements can fall off freely when the concrete model is damaged, which is very similar to the concrete particle falling off in the test.

Two materials were included in the concrete numerical model: mortar and coarse aggregate. The random generation of coarse aggregate was realized using Python language to process C3D8R element numbers in the INP file of the ABAQUS code, and the length, width, and height of coarse aggregate model are between $12 \mathrm{~mm}$ and $19 \mathrm{~mm}$ (Figure 11). C3D8R elements were used for both mortar and coarse aggregate, and $\mathrm{COH} 3 \mathrm{D} 8$ elements were embedded between C3D8R elements. The total numbers of $\mathrm{COH} 3 \mathrm{D} 8$ and C3D8R elements in the model were 164,400 and 56,000, respectively. For brittle heterogeneous materials, especially concrete materials, only linear elastic behavior is considered in C3D8R elements (Table 5). The elastic modulus, Poisson's ratio, and density of $\mathrm{COH} 3 \mathrm{D} 8$ elements were similar to those of surrounding C3D8R elements; however, COH3D8 elements also had tensile and shear strengths, which could be determined by splitting and shear tests (Table 5). In addition, related concrete studies have reported that the spacing between concrete particles is approximately $0.01 \mathrm{~mm}$ [32]; hence, the thickness of COH3D8 elements in the model was set as $0.01 \mathrm{~mm}$. 


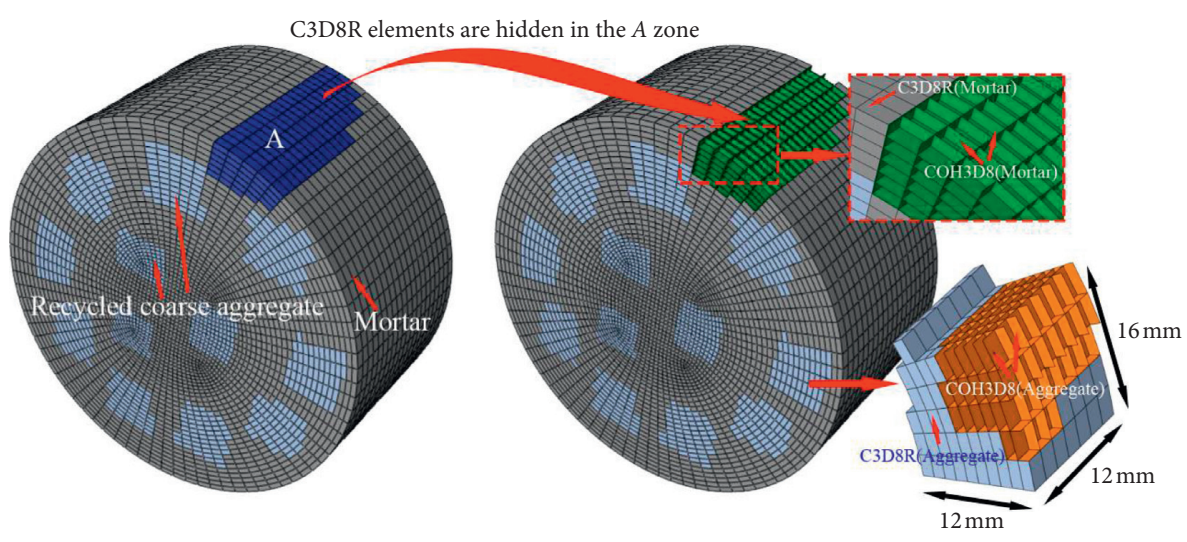

FIGURE 11: Batch embedding of cohesive elements and the random generation of coarse aggregate in the numerical model.

TABLE 5: Material parameters.

\begin{tabular}{|c|c|c|c|c|c|}
\hline Material & $E_{d}(\mathrm{MPa})$ & Poisson's ratio & $\rho\left(\mathrm{kg} \cdot \mathrm{m}^{-3}\right)$ & $\sigma_{0}(\mathrm{MPa})$ & $\tau_{c}(\mathrm{MPa})$ \\
\hline C3D8R (mortar) & 22,300 & 0.20 & 2310 & - & - \\
\hline C3D8R (recycled aggregate) & 47,200 & 0.23 & 2539.5 & - & - \\
\hline $\mathrm{COH} 3 \mathrm{D} 8$ (recycled aggregate) & 47,200 & 0.23 & 2539.5 & 35.62 & 53.43 \\
\hline $\mathrm{COH} 3 \mathrm{D} 8$ (mortar) & 22,300 & 0.20 & 2310 & 15.10 & 22.65 \\
\hline
\end{tabular}

According to the schematic view of the SHPB system in Figure 3, its simulation model was established. The linear elastic model was adopted for the incident and transmission bars. A hard contact without friction between the pressure bar and the specimen was considered. Stress waves in the R100-60 specimen are displayed in Figure 4.

4.5. Numerical Simulation Results. The numerical simulation results of the R100-60-1700 specimen are displayed in Figure 12, and the failure pattern of the numerical model was consistent with the test result.

During the dynamic loading process at $t=673-688 \mu \mathrm{s}$, stress concentration occurred at the incident loading end of the model. When the loading time was $t=792 \mu \mathrm{s}$, an extrusion protrusion appeared in the middle of the model. During the dynamic loading process at $t=847-870 \mu \mathrm{s}$, the element damage of the model was more serious, and the elements appeared to fall off. When the loading time was $t=910 \mu \mathrm{s}$, the volume of the model was greatly compressed, and a large number of elements at the loading end and middle part of the model fall off. When the loading time was $t=1024 \mu \mathrm{s}$, the mortar region in the model was completely crushed. At this moment, the failure phenomenon of the coarse aggregate region is exhibited in Figure 13. The failure phenomenon of residual coarse aggregate in the numerical model was consistent with that of the test specimen.

In order to gain further insight into the failure mechanism, the stress-strain curve obtained by the numerical

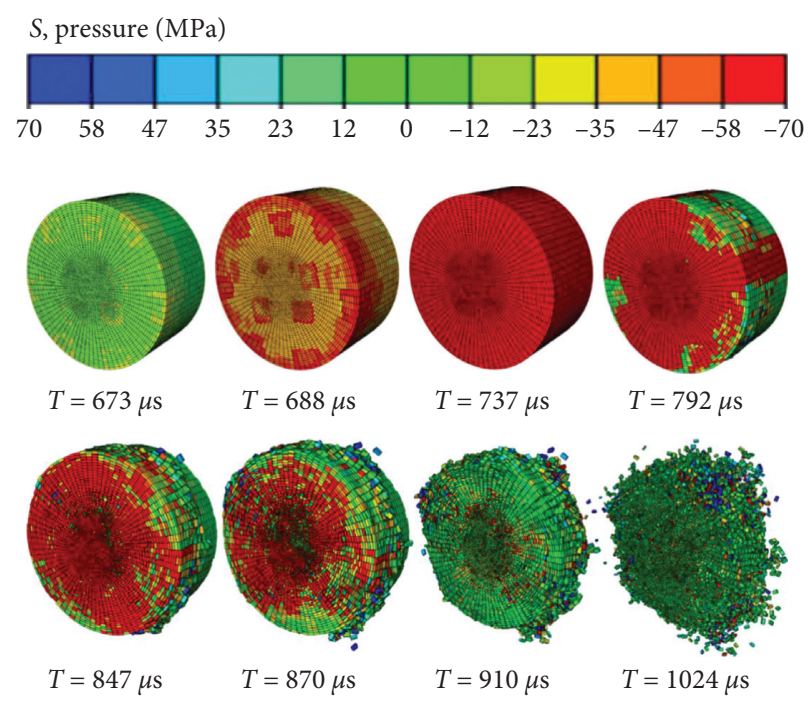

FIgURE 12: Numerical simulation results of the R100-60-1700 specimen.

simulation was compared with that obtained from the experiment (Figure 14(a)). It is noticeable that the stress-strain curve obtained by the numerical simulation was consistent with that obtained from the experiment, and the peak stress difference between the two curves was only $1.7 \%$, confirming the reliability of the numerical simulation. 

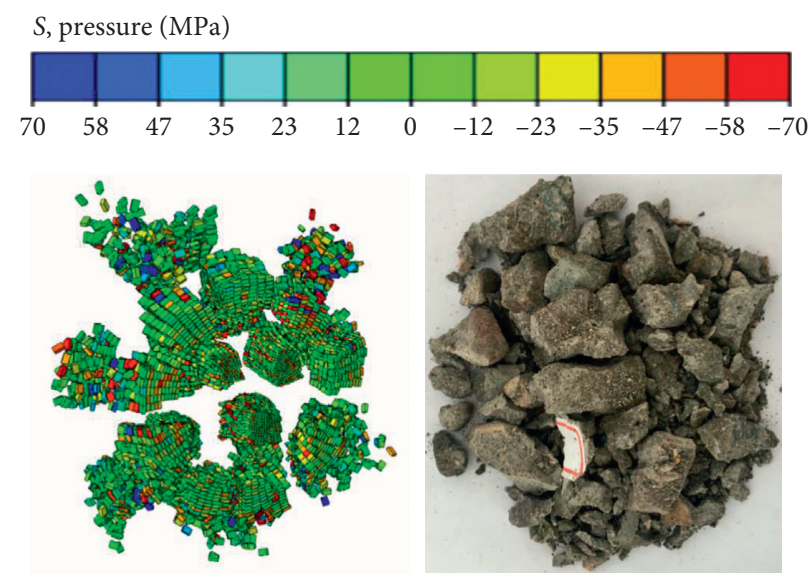

FiguRE 13: Failure phenomenon of coarse aggregate in the numerical model.

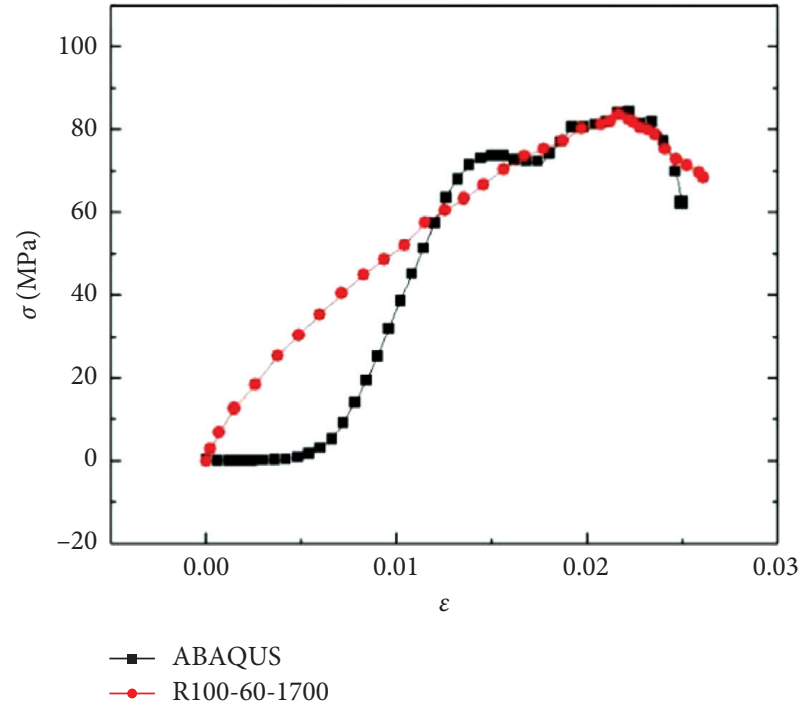

(a)

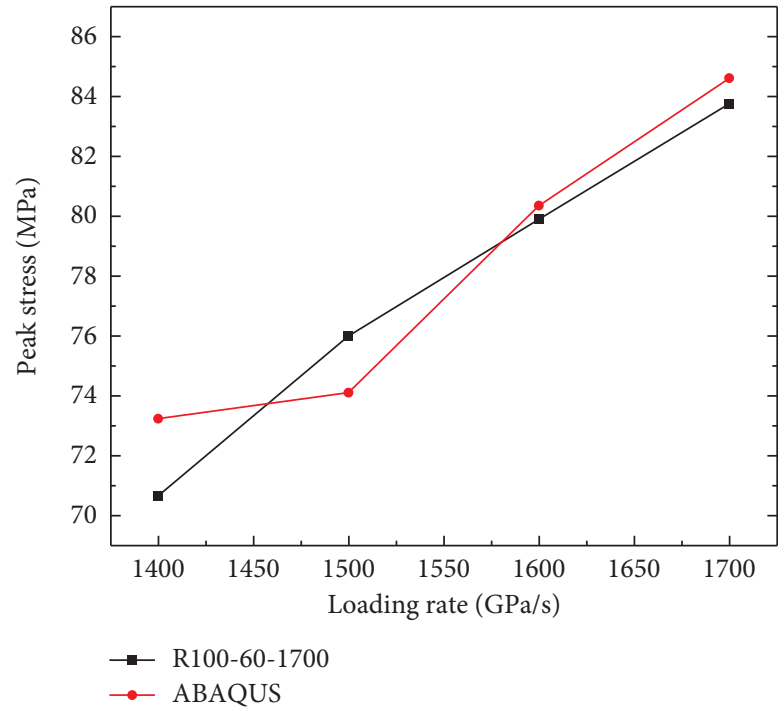

(b)

Figure 14: Comparison between the stress-strain curves and peak stress versus loading rate curves of the R100-60-1700 specimen and the numerical model. (a) Stress-strain curve. (b) Relationship between peak stress and loading rate.

Figure 14(b) displays the peak stress versus loading rate curves obtained from the simulation and the experiment. The maximum and minimum peak stress differences between the two curves were $3.5 \%$ and $0.6 \%$, respectively.

\section{Conclusions}

(1) The failure of the recycled concrete was divided into four grades under different loading rates. When the loading rates were $1400 \mathrm{GPa} / \mathrm{s}, 1500 \mathrm{GPa} / \mathrm{s}$, $1600 \mathrm{GPa} / \mathrm{s}$, and $1700 \mathrm{GPa} / \mathrm{s}$, the failure patterns of the concrete were graded as 1 to 4 , respectively.

(2) The peak strain of the recycled concrete was significantly higher than that of the ordinary concrete; however, its peak stress was lower than that of the ordinary concrete. When the replacement rate of
RCA reached $100 \%$, the peak stress decreased by $21 \%$.

(3) Under the same replacement rate of RCA, the toughness index of the recycled concrete increased with the increasing loading rate. In comparison to the recycled concretes containing $70 \%$ and $100 \%$ RCAs, the toughness index amplification of the recycled concrete containing 30\% RCAs was the most obvious.

(4) In the numerical model, cohesive elements of the mortar region were completely discrete, whereas those of the coarse aggregate region were only partially discrete. The failure pattern and mechanical properties of the numerical model were consistent with those of the test specimens, thus validating the reliability of the numerical simulation. 


\section{Data Availability}

The data used to support the findings of this study are included within the article.

\section{Conflicts of Interest}

The authors declare no conflicts of interest.

\section{Acknowledgments}

This work was financially supported by the National Natural Science Foundation of China (Grant nos. 11672194 and U19A2098). The authors thank LetPub (https://www.letpub. com) for its linguistic assistance during the preparation of this manuscript.

\section{References}

[1] J. Sun, Z. Wang, and Z. Chen, "Hydration mechanism of composite binders containing blast furnace ferronickel slag at different curing temperatures," Journal of Thermal Analysis and Calorimetry, vol. 131, no. 3, pp. 2291-2301, 2018.

[2] A. Tiwari, S. Singh, and R. Nagar, "Feasibility assessment for partial replacement of fine aggregate to attain cleaner production perspective in concrete: a review," Journal of Cleaner Production, vol. 135, no. 1, pp. 490-507, 2016.

[3] L. Liu, Y. Liu, K. Zhang, N. Song, H. Zhao, and F. Liu, "Influence of nickel-iron slag used as admixture on cement properties," Bulletin of the Chinese Ceramic Society, vol. 35, no. 6, pp. 1705-1710, 2016.

[4] X. Gao, H. Zhang, X. Yang, and K. Li, "A study on the application of Ni-Fe slag compound admixture in concrete," China Building Materials Science \& Technology, vol. 26, no. 1, pp. 23-26, 2017.

[5] B. Xi, R. Li, X. Zhao, Q. Dang, D. Zhang, and W. Tan, "Constraints and opportunities for the recycling of growing ferronickel slag in China," Resources, Conservation and Recycling, vol. 139, pp. 15-16, 2018.

[6] C. Fan, W. Ni, H. Yang, and J. Wu, "Preparation of cementitious materials from ferroalloy slag and its microscopic analysis," Bulletin of the Chinese Ceramic Society, vol. 26, no. 3, pp. 537-541, 2007.

[7] T. Yang, X. Yao, and Z. Zhang, "Geopolymer prepared with high-magnesium nickel slag: characterization of properties and microstructure," Construction and Building Materials, vol. 59, no. 1, pp. 188-194, 2014.

[8] Y. C. Choi and S. Choi, "Alkali-silica reactivity of cementitious materials using ferro-nickel slag fine aggregates produced in different cooling conditions," Construction and Building Materials, vol. 99, no. 30, pp. 279-287, 2015.

[9] K. Komnitsas, D. Zaharaki, and G. Bartzas, "Effect of sulphate and nitrate anions on heavy metal immobilisation in ferronickel slag geopolymers," Applied Clay Science, vol. 73, pp. 103-109, 2013.

[10] E. Dourdounis, V. Stivanakis, G. N. Angelopoulos et al., "High-alumina cement production from FeNi-ERF slag, limestone and diasporic bauxite," Cement and Concrete Research, vol. 34, no. 6, pp. 941-947, 2004.

[11] N. S. Katsiotis, P. E. Tsakiridis, D. Velissariou, M. S. Katsiotis, S. M. Alhassan, and M. Beazi, "Utilization of ferronickel slag as additive in portland cement: a hydration leaching study,"
Waste and Biomass Valorization, vol. 6, no. 2, pp. 177-189, 2015.

[12] X. Ding, K. Song, and D. Liu, "Effect of nickel iron slag powder only mixed and mixed with fly ash on the properties of concrete," Cement Engineering, no. 2, pp. 83-86, 2016.

[13] S. W. Tabsh and A. S. Abdelfatah, "Influence of recycled concrete aggregates on strength properties of concrete," Construction and Building Materials, vol. 23, no. 2, pp. 1163-1167, 2009.

[14] M. Etxeberria, E. Vázquez, A. Marí, and M. Barra, "Influence of amount of recycled coarse aggregates and production process on properties of recycled aggregate concrete," Cement and Concrete Research, vol. 37, no. 5, pp. 735-742, 2007.

[15] M. C. Limbachiya, T. Leelawat, and R. K. Dhir, "Use of recycled concrete aggregate in high-strength concrete," $M a$ terials and Structures, vol. 33, no. 9, pp. 574-580, 2000.

[16] M. C. Rao, S. K. Bhattacharyya, and S. V. Barai, "Behaviour of recycled aggregate concrete under drop weight impact load," Construction and Building Materials, vol. 25, no. 1, pp. 69-80, 2010.

[17] W. Li, Z. Luo, C. Long, C. Wu, W. H. Duan, and S. P. Shah, "Effects of nanoparticle on the dynamic behaviors of recycled aggregate concrete under impact loading," Materials \& Design, vol. 112, no. 15, pp. 58-66, 2016.

[18] M. Mastali, A. Dalvand, and A. R. Sattarifard, "The impact resistance and mechanical properties of reinforced selfcompacting concrete with recycled glass fibre reinforced polymers," Journal of Cleaner Production, vol. 124, no. 15, pp. 312-324, 2016.

[19] W. Li, Z. Luo, C. Wu, V. W. Y. Tam, W. H. Duan, and S. P. Shah, "Experimental and numerical studies on impact behaviors of recycled aggregate concrete-filled steel tube after exposure to elevated temperature," Materials \& Design, vol. 136, no. 15, pp. 103-118, 2017.

[20] J. Tao, Y. Chen, C. Tian, G. Chen, S. Li, and X. Huang, "Analysis of the inertial effect of the cylindrical specimen in SHPB system," Chinese Journal of Solid Mechanics, vol. 26, no. 1, pp. 107-110, 2005.

[21] H. Qiu, Z. Zhu, M. Wang et al., "Study on crack dynamic propagation behavior and fracture toughness in rock-mortar interface of concrete," Engineering Fracture Mechanics, vol. 228, no. 1, Article ID 106798, 2020.

[22] H. Qiu, Z. Zhu, M. Wang, F. Wang, C. Luo, and D. Wan, "Study of the failure properties and tensile strength of rockmortar interface transition zone using bi-material Brazilian discs," Construction and Building Materials, vol. 236, no. 10, Article ID 117551, 2020.

[23] Q. M. Li and H. Meng, "About the dynamic strength enhancement of concrete-like materials in a split Hopkinson pressure bar test," International Journal of Solids and Structures, vol. 40, no. 2, pp. 343-360, 2003.

[24] J. Zhu, S. Hu, and L. Wang, "An analysis of stress uniformity for concrete-like specimens during SHPB tests," International Journal of Impact Engineering, vol. 36, no. 1, pp. 61-72, 2009.

[25] F. Wang, M. Wang, M. Mousavi Nezhad, H. Qiu, P. Ying, and C. Niu, "Rock dynamic crack propagation under different loading rates using improved single cleavage semi-circle specimen," Applied Sciences, vol. 9, no. 22, p. 4944, 2019.

[26] L. Wang, B. Pang, Y. Chen, and K. Zhang, "Study on dynamic behavior and constitutive model of reactive powder concrete after high temperature treatment," Journal of High Pressure Physics, vol. 26, no. 4, pp. 361-368, 2012. 
[27] H. Su, J. Xu, E. Bai, X. Luo, and Y. Xi, "Experimental study on impact resistance of ceramic fiber reinforced concrete," Journal of Building Materials, vol. 16, no. 2, pp. 237-243, 2013.

[28] B. I. G. Barr, K. Liu, and R. C. Dowers, "A toughness index to measure the energy absorption of fibre reinforced concrete," International Journal of Cement Composites and Lightweight Concrete, vol. 4, no. 4, pp. 221-227, 1982.

[29] J. Zhou, J. Pan, and C. K. Y. Leung, "Mechanical behavior of fiber-reinforced engineered cementitious composites in uniaxial compression," Journal of Materials in Civil Engineering, vol. 27, no. 1, Article ID 04014111, 2015.

[30] G. Zhong, Y. Zhou, and Y. Xiao, "Stress-strain behavior of steel-polyviny alcohol hybrid fiber reinforced concrete under axial compression and tension," Engineering Mechanics, vol. 37, no. 1, pp. 111-120, 2020.

[31] G. I. Barenblatt, "The mathematical theory of equilibrium cracks in brittle fracture," Advances in Applied Mechanics, vol. 7, pp. 55-129, 1962.

[32] D. Bentz and E. Garboczi, "Computer modelling of interfacial transition zone microstructure and properties," in Engineering and Transport Properties of the Interfacial Transition Zone in Cementitous Composites, pp. 349-385, RILEM Publications, Paris, France, 1999. 